\title{
The combination of MELD score and ICG liver testing predicts length of stay in the ICU and hospital mortality in liver transplant recipients
}

\author{
Stephanie Klinzing ${ }^{1}$, Giovanna Brandi ${ }^{1}$, Paul A Stehberger ${ }^{1}$, Dimitri A Raptis ${ }^{2}$ and Markus Béchir ${ }^{\text {* }}$
}

\begin{abstract}
Background: Early prediction of outcome would be useful for an optimal intensive care management of liver transplant recipients. Indocyanine green clearance can be measured non-invasively by pulse spectrophometry and is closely related to liver function.

Methods: This study was undertaken to assess the predictive value of a combination of the model of end stage liver disease (MELD) score and early indocyanine plasma disappearance rates (ICG-PDR) for length of stay in the intensive care unit (ICU), length of stay in the hospital and hospital mortality in liver transplant recipients.

Results: Fifty consecutive liver transplant recipients were included in this post Hoc single-center study. ICG-PDR was determined within 6 hours after ICU admission. Endpoints were length of stay in the ICU, length of hospital stay and hospital mortality. The combination of a high MELD score (MELD >25) and a low ICG-PDR clearance (ICG-PDR $<20 \% /$ minute) predicts a significant longer stay in the ICU $(p=0.004)$, a significant longer stay in the hospital $(p<0.001)$ and a hospital mortality of $40 \%$ vs. $0 \%(p=0.003)$.

Conclusion: The combination of MELD scores and a singular ICG-PDR measurement in the early postoperative phase is an accurate predictor for outcome in liver transplant recipients. This easy-to-assess tool might be valuable for an optimal intensive care management of those patients.
\end{abstract}

Keywords: MELD score, Indocyanine green liver testing, Hospital mortality, Length of stay in the ICU

\section{Background}

In 2002, the United Network for Organ Sharing introduced a new allocation policy for cadaveric liver transplants based on the end-stage liver disease (MELD) scoring system [1].

However, while the MELD score is an accurate predictor of waiting list mortality $[2,3]$, recipient-derived methods including MELD [4-7] and, for example, the Child-Pugh score $[5,8]$ poorly predict mortality in liver transplant recipients. Similarly graft derived methods like the donor risk index, also has poor predictive value [9]. The 2008 Survival Outcomes Following Liver Transplant (SOFT) Score [10], on the other hand, incorporates 18 recipientand donor- derived factors as well as operative factors

\footnotetext{
* Correspondence: markus.bechir@paraplegie.ch

'Surgical Intensive Care Medicine, University Hospital of Zurich, Raemistrasse 100, CH-8091 Zurich, Switzerland

Full list of author information is available at the end of the article
}

and, as a result, accurately predicts short-term recipient survival following liver transplantation.

Due to the improvement in surgical techniques and a reduction in allograft rejection, the 1-year patient and graft survival is $90 \%[4,11,12]$, with the highest mortality rate during the early postoperative period in the critical care unit $[13,14]$. Major complications occurring in the early postoperative phase are mainly due to graft nonfunction, acute rejection, sepsis, neurological complications and haemorrhagic shock.

Only limited date on the critical care management of and complications in liver transplant recipients are available [15-18]. Therefore, an easy-to-assess test with good accuracy would be valuable for outcome prediction and risk stratification in the postoperative phase of liver transplant patients.

High MELD scores reflect the severity of liver disease before transplantation and are associated with postoperative

\section{Biomed Central}


morbidity and complication [4,19]. Less is known about factors which predict postoperative outcome of liver transplant recipients. The assessment of post-transplant liver function traditionally is based on several nonspecific liver function tests that are difficult to interpret and need serial observation [20]. Indocyanine green (ICG) is closely correlated with hepatic function due to its hepatic metabolization. It has proven to predict outcome in critically ill [21] and septic patients [22], but its relevance in liver transplantation is elusive $[23,24]$. Classically ICG measurements were performed either by spectrophotometry [25] or with a fiber-optic aortic catheter placed through the femoral artery [26]. Both methods correlate well with graft function, but are time consuming, expensive or invasive. On the other hand, the method of non-invasive ICG measurement based on pulse dye measurement using a finger-clip correlates well with the classical measurements [27], but it is non-invasive and easy to use.

Therefore we evaluated the predictive power of preoperative MELD, postoperative ICG measurement and a combination of these values regarding length of stay in the ICU, length of stay in the hospital and mortality by performing single and combined ROC analysis.

\section{Methods}

From September 2007 to June 2009, 50 consecutive patients who underwent transplantation at our center and received an ICG test within six hours after admission to the ICU were included in this Post Hoc analysis. Following approval by the local ethic committee (KEK Kantonale Ethik Kommission [Cantonal Ethical Committee] 4, Canton Zurich), all patients gave written informed consent before transplantation for postoperative data analysis.

\section{ICG liver test}

The ICG liver testing was performed noninvasively by pulse spectrophotometry (LiMON ${ }^{\circ}$, Pulsion Medical Systems AG, Munich, Germany). After intravenous injection ICG-bolus $(0.25 \mathrm{mg} / \mathrm{kg}$; ICG Pulsion Medical Systems AG, Munich, Germany), plasma ICG concentrations were determined by pulse spectrophotometry with a finger-clip sensor that detects two near-infrared wavelengths.

The plasma disappearance rate of ICG (ICG-PDR) was calculated automatically by the time course of the blood ICG concentration (normal value: ICG-PDR $\geq 16 \% /$ minute).

After ICU admission, volume was assessed with passive leg raise test and focused transthoracic echocardiography and corrected if necessary. ICG-PDR measurements were performed within 6 hours from admission to the ICU.

\section{Operative technique}

All livers were transplanted without a veno-venous bypass, as described by McCormack and colleagues [28].

\section{Baseline data}

Gender, age and body mass index were collected for recipients and donors. For recipients, uncorrected MELD scores, SAPS II as well the incidence of renal replacement therapy (RRT) and hepato-renal-syndrome (HRS) before transplantation were recorded. The values of creatinine, haematocrit, platelets, INR and bilirubin immediately prior to transplantation were gathered. Creatinine values for patients on RRT were excluded. HRS was defined according to the definitions by Arroy [29] and Salerno [30].

The incidence of cadaveric or living donors as well as extended donor criteria was registered. Extended donor criteria (marginal grafts) were defined as age of 65 years or older, cold ischemia time of 720 minutes or longer, or biopsy-proven steatosis (micro- or macrovascular in $\geq 60 \%$ of hepatocytes or $\geq 30 \%$ macrovascular steatosis) [31].

\section{ICU data}

The ICG-PDR was measured within the first 6 hours after admission, the factor V 24 hours after transplantation, and the peak values for bilirubin during the first postoperative week were recorded.

Data concerning length of ICU and hospital stay were collected and hospital mortality was recorded.

\section{Statistical analysis}

Continuous variables were compared with the MannWhitney U, or Kruskal-Wallis tests, where appropriate. Differences among proportions were compared using the Fischer's Exact or the Pearson $\chi^{2}$ tests, where appropriate. All $\mathrm{p}$ values were two-sided and considered statistically significant if $\mathrm{p} \leq 0.05$. Sensitivity, specificity, accuracy, diagnostic odds ratio (OR), and the receiver operator characteristic (ROC) curve were also calculated [32-36]. According to the results, a cut off of 4 days for length of stay in the ICU and 37 days for length of stay in the hospital was determined. Thereafter a logistic regression model including gender, age, BMI and the combined MELD/ICG score was performed. Statistical analysis was performed using SPSS Statistics version 20 (SPSS: An IBM Company, Chicago IL, 2012).

\section{Results}

Demographic data and baseline characteristics are shown in Table 1. The postoperative ICU results are presented in Table 2.

Twenty-seven patients stayed in the ICU for more than four days and thirteen patients had a hospital stay of more than thirty-seven days (Table 3). Patients with an ICU stay longer than four days were characterized by a significantly higher MELD score $(\mathrm{p}=0.007)$, significantly decreased ICG-PDR ( $p=0.001)$, significantly elevated peak bilirubin within the first postoperative week 
Table 1 Demographic data of the recipients and donors $(n=50)$

\begin{tabular}{|c|c|c|}
\hline & Recipient & Donor \\
\hline Male (\%) & 37 (74\%) & $36(72 \%)$ \\
\hline Female (\%) & $13(26 \%)$ & $14(28 \%)$ \\
\hline Age (yrs) & $51.3 \pm 11.1(16-67)$ & $53.2 \pm 17.2(19-86)$ \\
\hline BMI $\left(\mathrm{kg} / \mathrm{m}^{2}\right)$ & $25.7 \pm 4.73(16.6-42.9)$ & $24.3 \pm 3.3(16.0-31.0)$ \\
\hline MELD & $21 \pm 10.4(6-40)$ & \\
\hline RRT before TPL (\%) & $8(16 \%)$ & \\
\hline HRS before TPL (\%) & 17 (34\%) & \\
\hline SAPS ॥ & $30 \pm 19(0-91)$ & \\
\hline Creatinine $(\mu \mathrm{mol} / \mathrm{l})$ & $121 \pm 117(40-814)$ & \\
\hline Hematocrit (\%) & $31.4 \pm 7.6(18.8-49.6)$ & \\
\hline Platelets $\left(10^{3} / \mu \mathrm{l}\right)$ & $106 \pm 65(33-324)$ & \\
\hline INR & $1.5 \pm 0.6(0.9-4.3)$ & \\
\hline Bilirubin $(\mu \mathrm{mol} / \mathrm{l})$ & $148 \pm 198(5-875)$ & \\
\hline \multicolumn{3}{|l|}{ Etiology of liver disease } \\
\hline HCV (\%) & 17 (34\%) & \\
\hline HBV (\%) & $3(6 \%)$ & \\
\hline HCC (\%) & $10(20 \%)$ & \\
\hline Alcoholic liver cirrhosis (\%) & $6(12 \%)$ & \\
\hline Cholangiocarcinoma (\%) & $2(4 \%)$ & \\
\hline Others ${ }^{1}(\%)$ & $12(24 \%)$ & \\
\hline Cadaveric Donor (\%) & & $44(88 \%)$ \\
\hline Living Donor (\%) & & $6(12 \%)$ \\
\hline $\begin{array}{l}\text { Extended donor graft } \\
\text { criteria (\%) }\end{array}$ & & $16(32 \%)$ \\
\hline
\end{tabular}

Data expressed as mean \pm standard deviation (range). Abbreviations: BMI, body mass index; RRT, renal replacement therapy; TPL, transplantation; HRS, hepato-renal syndrome; SAPS, simplified acute physiology score; INR, international normalized ratio; $\mathrm{HCV}$, hepatitis $\mathrm{C}$ virus; $\mathrm{HBV}$, hepatitis $B$ virus; $\mathrm{HCC}$, hepatocellular carcinoma. Footnote: ${ }^{1}$ ) encompasses primary biliary cirrhosis, primary sclerosing cholangitis, autoimmune hepatitis liver cirrhosis, Morbus Wilson, alpha-1-antitrypsin-defiency, acute liver failure, cryptogenic liver cirrhosis, Morbus Osler, polycyclic liver disease, recurrent intrahepatic cholestasis, vanishing bile duct syndrome, haemangioendothelioma.

$(\mathrm{p}=0.03)$ and significantly decreased factor $\mathrm{V}$ within the first 24 hours after operation $(p=0.03)$. Patients with a prolonged hospital stay over 37 days were characterized by significantly higher MELD score $(\mathrm{p}<0.001)$ and significantly elevated peak bilirubin within the first postoperative week $(\mathrm{p}=0.008)$.

A ROC analysis was performed, which is presented in Table 4 and Figure 1. According to the determined cut off value, a MELD > 25 was significant for prolonged ICU stay over four days (OR 4.12, 95\% confidence interval $(95 \% \mathrm{CI}) 1.2-13.8, \mathrm{p}=0.024)$ and a prolonged hospital stay over 37 days (OR 13.0, 95\% CI $2.5-68.6, \mathrm{p}=0.001$ ). ICG-PDR $<20 \% / \mathrm{min}$ was significant for prolonged ICU stay (OR 3.54, 95\% CI 1.1-11.8, $\mathrm{p}=0.047$ ) and prolonged hospital stay (OR 4.67, 95\% CI 1.20-18.34, $\mathrm{p}=0.027$ ) respectively. Peak bilirubin $>100 \mu \mathrm{mol} / \mathrm{l}$ within the first
Table 2 Postoperative ICU data $(\mathbf{n}=\mathbf{5 0})$

\begin{tabular}{ll}
\hline ICG-PDR $(\% / \mathrm{min})^{1}$ & $19.5 \pm 7.7(4.2-34)$ \\
Bilirubin $(\mu \mathrm{mol} /)^{2}$ & $133 \pm 115(17-568)$ \\
Factor V $(\%)^{3}$ & $57 \pm 29(4-114)$ \\
ICU stay (days) & $11.6 \pm 21.9(1-93)$ \\
Hospital stay (days) & $31.4 \pm 28.0(8-128)$ \\
Hospital Mortality (\%) & $4(8 \%)$
\end{tabular}

Data expressed as mean \pm standard deviation (range). Abbreviations: ICG-PDR, indocyanine green plasma disappearance rate. Footnotes: ${ }^{1}$ ) determined within 6 hours after ICU admission, ${ }^{2}$ ) peak values within 7 days, ${ }^{3}$ ) after 24 hours.

postoperative week was significant for a prolonged hospital stay $(\mathrm{OR}=0.063,95 \%$ CI $0.007-0.54, \mathrm{p}=0.01)$ but not for prolonged ICU stay $(\mathrm{OR}=0.39,95 \% \mathrm{CI}$ $0.12-1.21, \mathrm{p}=0.10)$. Factor $\mathrm{V}$ measurement 24 hours postoperatively failed to achieve significance for both length of stay in the ICU $(\mathrm{OR}=0.35,95 \% \mathrm{CI} 0.11-1.13$, $\mathrm{p}=0.09)$ and length of hospital stay $(\mathrm{OR}=2.13 ; 95 \% \mathrm{CI}$ $0.56-8.16, \mathrm{p}=0.34)$. Four patients $(8 \%)$ died during hospitalization, characterized by significantly higher MELD scores $(\mathrm{p}=0.032)$ and significantly decreased ICG-PDR $(\mathrm{p}=0.026)$ compared to survivors. Peak bilirubin $(\mathrm{p}=0.12)$ and factor $\mathrm{V}(\mathrm{p}=0.31)$ were not significantly different between survivors and non-survivors.

Based on these findings, a combination of MELD and ICG-PDR was tested. A positive MELD/ICG-PDR combination was defined as a high MELD score (MELD score $>25$ ) and a decreased ICG-PDR (ICG-PDR $<20 \% / \mathrm{min}$ ), while all other possible combinations were defined to be a negative combination (Table 5).

A positive MELD and ICG-PDR combination predicted a twice as long ICU length of stay of median 9 days $(\mathrm{p}=0.004)$ and a twice as long hospital stay of median 42 days $(\mathrm{p}<0.001)$ compared to all other possible combinations. Hospital Mortality in case of positive combination was $40 \%$, while it was $0 \%$ in case of negative combination $(\mathrm{p}=0.003)$.

A multivariate analysis of ICU length stay selected the MELD/ICG combination as the most prediciting factor, while OR could not be calculated because all cases were discriminated. BMI was significant in this analysis with $\mathrm{p}=0.007$ (OR 9.61, 95\% CI 1.88-26.5). Gender and age were not significant in this analysis $(\mathrm{p}=0.16$ and $\mathrm{p}=0.11$ respectively). Concerning Hospital length of stay, the MELD/ICG combination was significant with $\mathrm{p}=0.006$ (OR 64.17, 95\% CI 3.3-1253) and age was significant with $\mathrm{p}=0.045$ (OR 22.63, 95\% CI 1.08-415.2). Gender and BMI were not significant in this analysis $(\mathrm{p}=0.61$ and $\mathrm{p}=0.60$ respectively).

\section{Discussion}

The major new findings of this study - undertaken to determine whether an easy-to-use combination of a singular ICG-PDR measurement early after transplantation 
Table 3 ICU and hospital stay grouped data

\begin{tabular}{lllllll}
\hline & $\begin{array}{l}\text { ICU stay } \leq \mathbf{4} \text { days } \\
(\mathbf{n}=\mathbf{2 3})\end{array}$ & $\begin{array}{l}\text { ICU stay }>\mathbf{4} \text { days } \\
(\mathbf{n}=\mathbf{2 7})\end{array}$ & $\mathbf{p}$ & $\begin{array}{l}\text { Hospital stay } \leq \mathbf{3 7} \text { days } \\
\mathbf{( n = 3 7 )}\end{array}$ & $\begin{array}{l}\text { Hospital stay }>\mathbf{3 7} \text { days } \\
(\mathbf{n}=\mathbf{1 3})\end{array}$ \\
\hline Age $(\mathrm{yrs})$ & $50(45-58)$ & $55(48-61)$ & 0.11 & $50(45-58)$ & $58(51-63)$ \\
BMI $\left(\mathrm{kg} / \mathrm{m}^{2}\right)$ & $23.8(21.1-26.6)$ & $26.4(25.0-28.6)$ & 0.04 & $25.4(22.7-28.5)$ & $25.5(24.2-26.2)$ \\
MELD & $14(86-27)$ & $26(18-32)$ & 0.007 & $18(10-26)$ & $28(26-34)$ & 0.033 \\
ICG-PDR $(\% / \mathrm{min})^{1}$ & $23.4(18.7-26.7)$ & $16.6(8.8-22.8)$ & 0.001 & $22.8(15.5-25.3)$ & $17.6(10.1-20.8)$ \\
Bilirubin $(\mu \mathrm{mol} /)^{2}$ & $94(22-149)$ & $133(61-214)$ & 0.03 & $88(37-156)$ & $162(116-214)$ & 0.72 \\
Factor $\mathrm{V}(\%)^{3}$ & $71(41-92)$ & $45(27-66)$ & 0.03 & $53(30-73)$ & $66(49-83)$ & 0.008 \\
\hline
\end{tabular}

Data expressed as median ( $25^{\text {th }}-75^{\text {th }}$ Percentile). Footnotes: $\left.{ }^{1}\right)$ determined within 6 hours after ICU admission, $\left.{ }^{2}\right)$ peak values within 7 days, $\left.{ }^{3}\right)$ after 24 hours.

and MELD correctly predicts postoperative ICU stay, hospital stay and hospital mortality - are that the positive combination of a high MELD score and a low ICGPDR predicts a significantly longer stay in the ICU (9 days vs. 4 days) and a significantly longer hospital stay (42 days vs. 22 days) as well as a significantly higher hospital mortality ( $40 \%$ vs. $0 \%$ ) compared to liver transplant recipients with a negative score.

The main limitations of our study are its small sample size and the post-hoc design, but nevertheless the results are promising and should be validated in another prospective collected dataset of liver transplant patients.

Our easy-to-use assessment combines the MELD score, for which it has been proven that high scores are associated with a prolonged postoperative course $[4,19]$ with an early postoperative ICG-PDR measurement of global liver function.

Low ICG-PDR values in the early postoperative phase of liver transplant recipients predict complications during the early postoperative period $[23,24]$ while normal values have been shown to predict an uncomplicated postoperative course [37]. Outcome prediction by ICG-PDR values has yielded conflicting results $[24,37,38]$.

Measurement of ICG-PDR is an accurate test for evaluating liver function, but, as shown by Levesque's results [23], its limitation is the lack to identify the underlying cause of a dysfunction. ICG-PDR is a test for global hepato-splanchnic blood flow and biliary excretion. Therefore, changes in ICGPDR may be due to local disturbances in hepatic blood flow or systemic disturbances. It has been proved that absence of flow in the hepatic artery and primary graft dysfunction or non-function leads to diminished ICG-PDR [39,40]. Moreover, it has been shown that ICG-PDR in patients with septic shock is reduced due to hepatocellular dysfunction [22]. For sepsis, it has been shown that recovery and survival is related to the course of repeated ICG-PDR measurements, where continuously low ICG-PDR over time is associated high mortality $[22,23]$.

Table 4 Receiver operating characteristic analysis of MELD, ICG-PDR, bilirubin and factor $\mathbf{V}$ to predict the length of stay in the ICU and in the hospital as well as hospital mortality

\begin{tabular}{|c|c|c|c|c|c|}
\hline & Cut-off value & AUC & Sensitivity (\%) & Specificity (\%) & $p$ \\
\hline \multicolumn{6}{|l|}{ ICU stay } \\
\hline MELD & 25 & 0.67 & 63 & 74 & 0.05 \\
\hline ICG-PDR (\%/min) ${ }^{1}$ & 20 & 0.77 & 70 & 74 & 0.001 \\
\hline Bilirubin $(\mu \mathrm{mol} / \mathrm{l})^{2}$ & 110 & 0.68 & 67 & 65 & 0.03 \\
\hline Factor $V(\%)^{3}$ & 40 & 0.75 & 67 & 74 & 0.002 \\
\hline \multicolumn{6}{|l|}{ Hospital stay } \\
\hline MELD & 23 & 0.81 & 100 & 54 & 0.001 \\
\hline ICG-PDR (\%/min) ${ }^{1}$ & 20 & 0.67 & 77 & 62 & 0.08 \\
\hline Bilirubin $\left(\mu \mathrm{mol} / \mathrm{I}^{2}{ }^{2}\right.$ & 110 & 0.75 & 92 & 62 & 0.01 \\
\hline Factor V $(\%)^{3}$ & 50 & 0.52 & 77 & 40 & 0.80 \\
\hline \multicolumn{6}{|l|}{ Hospital mortality } \\
\hline MELD & 25 & 0.85 & 100 & 59 & 0.02 \\
\hline ICG-PDR (\%/min) ${ }^{1}$ & 20 & 0.79 & 100 & 59 & 0.05 \\
\hline Bilirubin $\left(\mu \mathrm{mol} / \mathrm{I}^{2}\right.$ & 110 & 0.68 & 100 & 54 & 0.25 \\
\hline Factor V $(\%)^{3}$ & 40 & 0.72 & 100 & 44 & 0.16 \\
\hline
\end{tabular}

Abbreviations: AUC, area under the curve. Footnotes: ${ }^{1}$ ) determined within 6 hours after ICU admission, ${ }^{2}$ ) peak values within 7 days, ${ }^{3}$ ) after 24 hours. 

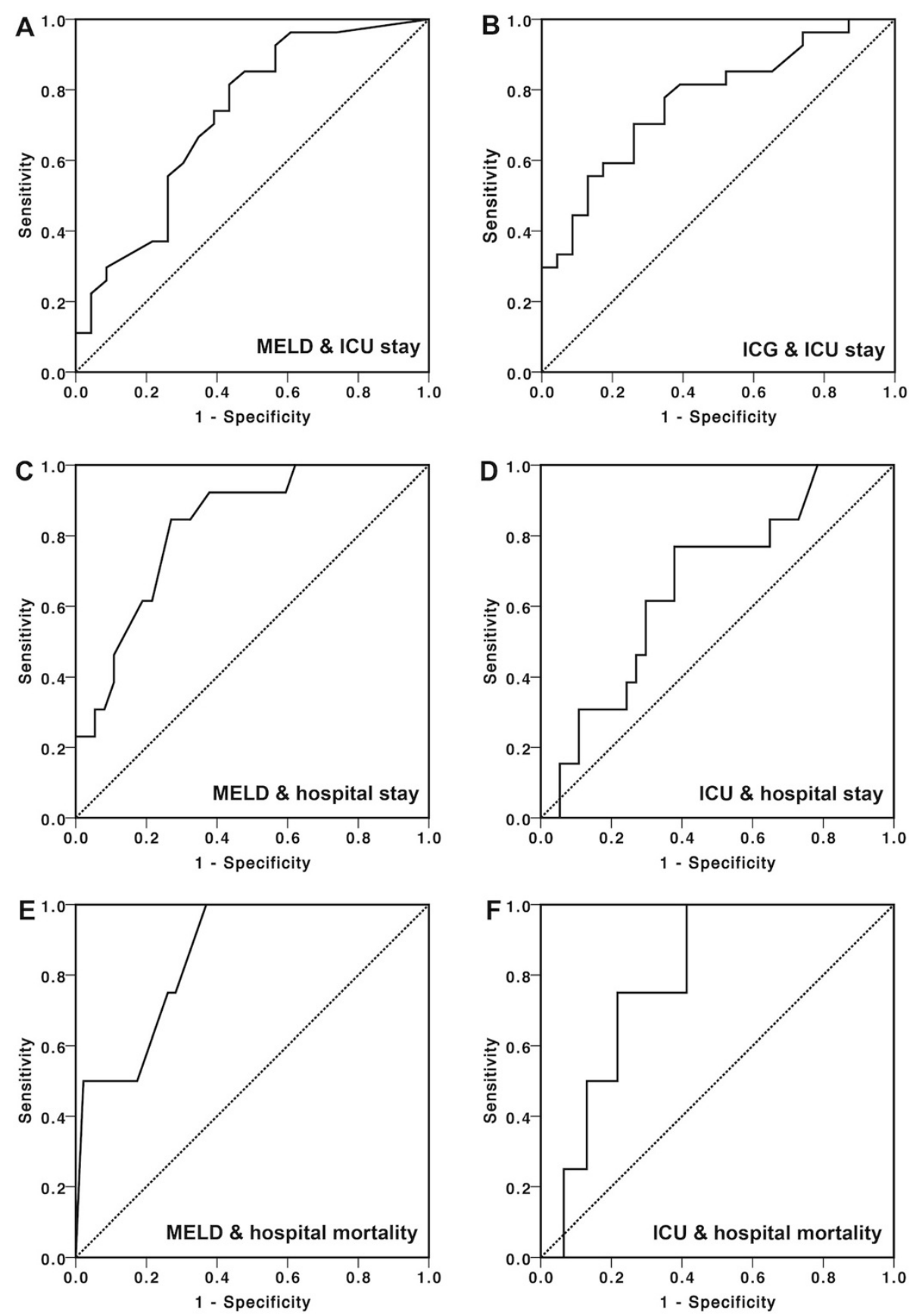

Figure 1 ROC curve analysis of parameters with different clinical outcomes. (A) Area under the curve (AUC) for MELD and ICU stay ( $\leq 4$ vs. $>4$ ), (B) ICG and ICU stay, (C) MELD and hospital stay ( $\leq 37 \mathrm{vs.}>37$ ), (D) ICG and hospital stay, (E) MELD and hospital mortality, and (F) ICG and hospital mortality.

Clinical benefit of our findings is risk stratification: Due to early assessment in the postoperative course, the combination of MELD scores and early postoperative ICG-PDR measurement might be valuable to identify risk patients in term of prolonged postoperative course and increased mortality and to prompt appropriate intensive care actions without time delay. This includes reassurement of hepatic blood flow by Doppler ultrasound, angiographic computed tomography or arteriography as well as calculated volume management and early goal-directed therapy in case of sepsis [41]. The negative combination of MELD scores and ICG-PDR 


\begin{tabular}{|c|c|c|c|}
\hline & $\begin{array}{l}\text { Positive } \\
\text { combination }\end{array}$ & $\begin{array}{l}\text { Negative } \\
\text { combination }\end{array}$ & $p$ \\
\hline ICU stay, median (IQR) & $9(5-43)$ & $4(3-6)$ & 0.004 \\
\hline Hospital stay, median (IQR) & $42(21-74)$ & $22(15-28)$ & $<0.001$ \\
\hline Hospital mortality, n (\%) & $4(40 \%)$ & $0(0 \%)$ & 0.003 \\
\hline
\end{tabular}

Positive combination: MELD $>25$ and ICG-PDR $<20 \% / \mathrm{min}$. Negative combination: all other combinations. Abbreviations: IQR, interquartile range, SEM, standard error of mean.

seems to identify recipients with short postoperative course and low mortality. This negative predictive value is in agreement with the ICG-PDR data reported by Schneider [37] and may be useful as a criterion for transferring patients from the ICU to a peripheral ward and allows optimal utilisation of the ICU resources.

While the combination of the MELD score and a singular ICG-PDR measurement in the early postoperative phase and BMI were identified as predictors of ICU length of stay, the combination of MELD score and ICG-PDR and age were identified as predictors for hospital length of stay. Therefore, the MELD and ICG-PDR combination seems to be the best predictor and risk stratificator in liver transplanted recipients admitted to the ICU in terms of ICU length of stay, hospital length of stay and hospital mortality.

\section{Conclusion}

In conclusion, the combination of the preoperative MELD score and a singular ICG-PDR measurement in the early postoperative phase (within six hours) is an interesting and easy to assess tool that should be addressed in a larger cohort of patients to evaluate its usefulness in terms of risk stratification and outcome prediction.

\section{Abbreviations \\ BMI: Body mass index; HBV: Hepatitis B virus; HCC: Hepatocellular carcinoma; HCV: Hepatitis C virus; HRS: Hepato-renal-syndrome; ICU: Intensive care unit; ICG: Indocyanine green; ICG-PDR: Indocyanine green plasma disappearance rate; INR: International normalized ratio; MELD: Model of end stage liver disease; RRT: Renal replacement therapy; SAPS II: Simplified acute physiology score II; SOFT score: Survival Outcomes Following Liver Transplant score; TPL: Transplantation.}

\section{Competing interests}

The authors declare that they have no competing interests.

\section{Authors' contributions}

MB and SK designed the study, PS performed the study, GB collected data and drafted the manuscript, DAR analysed data, SK and MB wrote the paper. All authors read and approved the final manuscript.

\section{Author details}

'Surgical Intensive Care Medicine, University Hospital of Zurich, Raemistrasse 100, CH-8091 Zurich, Switzerland. ${ }^{2}$ Department of Visceral- and Transplantation Surgery, University Hospital of Zurich, Zurich, Switzerland.
Received: 27 June 2013 Accepted: 27 October 2014

Published: 15 November 2014

\section{References}

1. Kamath PS, Wiesner RH, Malinchoc M, Kremers W, Therneau TM, Kosberg CL, D'Amico G, Dickson ER, Kim WR: A model to predict survival in patients with end-stage liver disease. Hepatology 2001, 33(2):464-470.

2. Wiesner R, Edwards E, Freeman R, Harper A, Kim R, Kamath P, Kremers W, Lake J, Howard T, Merion RM, Wolfe RA, Krom R, United Network for Organ Sharing Liver Disease Severity Score Committee: Model for end-stage liver disease (MELD) and allocation of donor livers. Gastroenterology 2003, 124(1):91-96.

3. Ravaioli M, Grazi GL, Ballardini G, Cavrini G, Ercolani G, Cescon M, Zanello M, Cucchetti A, Tuci F, Del Gaudio M, Varotti G, Vetrone G, Trevisani F, Bolondi L, Pinna AD: Liver transplantation with the Meld system: a prospective study from a single European center. Am J Transplant 2006, 6(7):1572-1577.

4. Oberkofler CE, Dutkowski P, Stocker R, Schuepbach RA, Stover JF, Clavien PA, Bechir M: Model of end stage liver disease (MELD) score greater than 23 predicts length of stay in the ICU but not mortality in liver transplant recipients. Crit Care 2010, 14(3):R117.

5. Brown RS Jr, Kumar KS, Russo MW, Kinkhabwala M, Rudow DL, Harren P, Lobritto S, Emond JC: Model for end-stage liver disease and ChildTurcotte-Pugh score as predictors of pretransplantation disease severity, posttransplantation outcome, and resource utilization in United Network for Organ Sharing status 2A patients. Liver Transp/ 2002, 8(3):278-284.

6. Desai NM, Mange KC, Crawford MD, Abt PL, Frank AM, Markmann JW, Velidedeoglu E, Chapman WC, Markmann JF: Predicting outcome after liver transplantation: utility of the model for end-stage liver disease and a newly derived discrimination function. Transplantation 2004, 77(1):99-106

7. Jacob M, Copley LP, Lewsey JD, Gimson A, Toogood GJ, Rela M, van der Meulen JH, UK and Ireland Liver Transplant Audit: Pretransplant MELD score and post liver transplantation survival in the UK and Ireland. Liver Transp/ 2004, 10(7):903-907.

8. Chung IS, Park M, Ko JS, Gwak MS, Kim GS, Lee SK: Which score system can best predict recipient outcomes after living donor liver transplantation? Transplant Proc 2012, 44(2):393-395.

9. Feng S, Goodrich NP, Bragg-Gresham JL, Dykstra DM, Punch JD, DebRoy MA, Greenstein SM, Merion RM: Characteristics associated with liver graft failure: the concept of a donor risk index. Am J Transplant 2006, 6(4):783-790.

10. Rana A, Hardy MA, Halazun KJ, Woodland DC, Ratner LE, Samstein B, Guarrera JV, Brown RS Jr, Emond JC: Survival outcomes following liver transplantation (SOFT) score: a novel method to predict patient survival following liver transplantation. Am J Transplant 2008, 8(12):2537-2546.

11. Organ Procurement and Transplantation Network. In 2011. http://www. sitr.org/.

12. Santoyo J, Suarez MA, Fernandez-Aguilar JL, Perez Daga JA, Sanchez-Perez B, Ramirez C, Aranda JM, Rodriguez-Canete A, Gonzalez-Sanchez A: True impact of the indication of cirrhosis and the MELD on the results of liver transplantation. Transplant Proc 2006, 38(8):2462-2464.

13. Jung B, Cisse M, Chanques G, Arsac E, Bismuth M, Panaro F, Perrigault PF Souche B, Gallix B, Verzilli D, Delay JM, Navarro F, Pageaux GP, Jaber S: Causes of early mortality after liver transplantation: a twenty-years single centre experience. Ann Fr Anesth Reanim 2011, 30(12):899-904.

14. Medeiros DM, Oliveira AC, Barros MF, Cury RA, Sette H Jr, Abdala E, Canedo LF, Makdissi FF, Andraus W, Martino RB, Rocha-Santos V, Figueira ER, Machado MA, Carrilho FJ, Cançado EL, Bacchella T, Machado MC: Early mortality in liver transplantation: bilirubin as predictor of outcome. Transplant Proc 2004, 36(4):931-932.

15. Karvellas CJ, McPhail M, Pink F, Asthana S, Muiesan P, Heaton N, Auzinger G, Bernal W, Eltringham I, Wendon JA: Bloodstream infection after elective liver transplantation is associated with increased mortality in patients with cirrhosis. J Crit Care 2011, 26(5):468-474.

16. Levesque E, Hoti E, Azoulay D, Honore I, Guignard B, Vibert E, Ichai P, Antoun F, Saliba F, Samuel D: Pulmonary complications after elective liver transplantation-incidence, risk factors, and outcome. Transplantation 2012, 94(5):532-538

17. Razonable RR, Findlay JY, O'Riordan A, Burroughs SG, Ghobrial RM, Agarwal B, Davenport A, Gropper M: Critical care issues in patients after liver transplantation. Liver Transpl 2011, 17(5):511-527. 
18. Saner FH, Sotiropoulos GC, Radtke A, Fouzas I, Molmenti EP, Nadalin S, Paul A Intensive care unit management of liver transplant patients: a formidable challenge for the intensivist. Transplant Proc 2008, 40(9):3206-3208.

19. Ferraz-Neto BH, Zurstrassen MP, Hidalgo R, Meira-Filho SP, Rezende MB, Paes AT, Afonso RC: Analysis of liver transplantation outcome in patients with MELD Score $>$ or $=30$. Transplant Proc 2008, 40(3):797-799.

20. Shaked A, Nunes FA, Olthoff KM, Lucey MR: Assessment of liver function: pre- and peritransplant evaluation. Clin Chem 1997, 43(8 Pt 2):1539-1545.

21. Sakka SG, Reinhart K, Meier-Hellmann A: Prognostic value of the indocyanine green plasma disappearance rate in critically ill patients. Chest 2002, 122(5):1715-1720.

22. Kimura S, Yoshioka T, Shibuya M, Sakano T, Tanaka R, Matsuyama S: Indocyanine green elimination rate detects hepatocellular dysfunction early in septic shock and correlates with survival. Crit Care Med 2001, 29(6):1159-1163.

23. Levesque E, Saliba F, Benhamida S, Ichai P, Azoulay D, Adam R, Castaing D, Samuel D: Plasma disappearance rate of indocyanine green: a tool to evaluate early graft outcome after liver transplantation. Liver Transp/ 2009, 15(10):1358-1364.

24. Olmedilla L, Perez-Pena JM, Ripoll C, Garutti I, de Diego R, Salcedo M, Jimenez C, Banares R: Early noninvasive measurement of the indocyanine green plasma disappearance rate accurately predicts early graft dysfunction and mortality after deceased donor liver transplantation. Liver Transp/ 2009, 15(10):1247-1253.

25. Hori T, lida T, Yagi S, Taniguchi K, Yamamoto C, Mizuno S, Yamagiwa K, Isaji S, Uemoto S: K(ICG) value, a reliable real-time estimator of graft function, accurately predicts outcomes in adult living-donor liver transplantation. Liver Transp/ 2006, 12(4):605-613.

26. Diaz S, Perez-Pena J, Sanz J, Olmedilla L, Garutti I, Barrio JM: Haemodynamic monitoring and liver function evaluation by pulsion cold system Z-201 (PCS) during orthotopic liver transplantation. Clin Transplant 2003, 17(1):47-55.

27. Faybik P, Krenn CG, Baker A, Lahner D, Berlakovich G, Steltzer H, Hetz H: Comparison of invasive and noninvasive measurement of plasma disappearance rate of indocyanine green in patients undergoing liver transplantation: a prospective investigator-blinded study. Liver Transp/ 2004, 10(8):1060-1064.

28. McCormack L, Selzner M, Clavien P-A: The Transplant Operation. In Medical Care of Liver Transplantation. Edited by Killenberg P, Clavien PA. Oxford, England: Blackwell Publishing; 2006.

29. Arroyo V, Gines P, Gerbes AL, Dudley FJ, Gentilini P, Laffi G, Reynolds TB, Ring-Larsen $\mathrm{H}$, Scholmerich J: Definition and diagnostic criteria of refractory ascites and hepatorenal syndrome in cirrhosis. Int Ascites Club Hepatol 1996, 23(1):164-176.

30. Salerno F, Gerbes A, Gines P, Wong F, Arroyo V: Diagnosis, prevention and treatment of hepatorenal syndrome in cirrhosis. Gut 2007, 56(9):1310-1318.

31. Merion RM, Goodrich NP, Feng S: How can we define expanded criteria for liver donors? J Hepatol 2006, 45(4):484-488.

32. Kirshwood BR, Sterne JAC: Essential Medical Statistics. In 2nd edition. Malden (Massachusetts, USA): Blackwell Science LTD; 2003.

33. Youden WJ: Index for rating diagnostic tests. Cancer 1950, 3(1):32-35.

34. Kraemer HC: Reconsidering the odds ratio as a measure of $2 \times 2$ association in a population. Stat Med 2004, 23(2):257-270.

35. Glas AS, Lijmer JG, Prins MH, Bonsel GJ, Bossuyt PM: The diagnostic odds ratio: a single indicator of test performance. J Clin Epidemiol 2003, 56(11):1129-1135.

36. Obuchowski NA: Receiver operating characteristic curves and their use in radiology. Radiology 2003, 229(1):3-8.

37. Schneider L, Spiegel M, Latanowicz S, Weigand MA, Schmidt J, Werner J, Stremmel W, Eisenbach C: Noninvasive indocyanine green plasma disappearance rate predicts early complications, graft failure or death after liver transplantation. Hepatobiliary Pancreat Dis Int 2011, 10(4):362-368.

38. Escorsell A, Mas A, Fernandez J, Garcia-Valdecasas JC: Limitations of use of the noninvasive clearance of indocyanine green as a prognostic indicator of graft function in liver transplantation. Transplant Proc 2012, 44(6):1539-1541.

39. Krenn CG, Schafer B, Berlakovich GA, Steininger R, Steltzer $H$, Spiss CK: Detection of graft nonfunction after liver transplantation by assessment of indocyanine green kinetics. Anesth Analg 1998, 87(1):34-36.
40. Yamanaka N, Okamoto E, Kato T, Fujihara S, Sasase S, Oriyama T, Fujimoto J, Furukawa K, Kawamura E, Tomoda F: Usefulness of monitoring the ICG retention rate as an early indicator of allograft function in liver transplantation. Transplant Proc 1992, 24(4):1614-1617.

41. Rivers E, Nguyen B, Havstad S, Ressler J, Muzzin A, Knoblich B, Peterson E, Tomlanovich M: Early goal-directed therapy in the treatment of severe sepsis and septic shock. N Engl J Med 2001, 345(19):1368-1377.

doi:10.1186/1471-2253-14-103

Cite this article as: Klinzing et al:: The combination of MELD score and ICG liver testing predicts length of stay in the ICU and hospital mortality in liver transplant recipients. BMC Anesthesiology 2014 14:103.

\section{Submit your next manuscript to BioMed Central and take full advantage of:}

- Convenient online submission

- Thorough peer review

- No space constraints or color figure charges

- Immediate publication on acceptance

- Inclusion in PubMed, CAS, Scopus and Google Scholar

- Research which is freely available for redistribution

Submit your manuscript at www.biomedcentral.com/submit
C) BioMed Central 